IDEAS IN ECRLGGY AND EVILUTION 6: 44-45, 2013

doi:10.4033/iee.2013.6.7.c

(C) 2013 The Author. (C) Ideas in Ecology and Evolution 2013

Received 24 May 2013; Accepted 26 June 2013

\title{
Commentary
}

\section{Uses for Twitter across disciplines and throughout the scientific process}

\author{
Lisa M. Federer \\ Lisa M. Federer (Imfederer@library.ucla.edu), UCLA Louise M. Darling Biomedical Library, University of \\ California-Los Angeles, Los Angeles, CA
}

Perhaps the best evidence of the validity of Darling et al.'s (2013) article, "The role of Twitter in the life cycle of a scientific publication" is its own Twitter life cycle. I read the email inviting me to review the paper on my smartphone in the back of a taxi taking me from the airport to a conference, and when I opened my Twitter app to catch up on what had happened at the conference so far, I found that two people I follow had already tweeted a link to the article in arXiv. As of this writing, the article has been Tweeted 540 times according to Altmetric, putting it in the top 5\% of all articles ranked by attention - all before my deadline to review it for publication has even passed.

As this article argues, and as its meteoric rise in popularity demonstrates, Twitter and other web technologies have led to significant changes in how scientific knowledge is created and disseminated. However, while Darling et al.'s (2013) examples from the marine ecology and conservation community are compelling, I argue that it may be premature to extrapolate these findings to the broader scientific community, particularly with regard to the authors' discussion of "open science in real time." The cultures surrounding and attitudes toward scientific openness can differ widely from one field of science to the next. For example, Tenopir et al.'s (2011) investigation of attitudes towards data sharing reveals significant differences across subject disciplines. Notably, respondents from the environmental sciences and ecology displayed the most willingness to share their data, with $81.6 \%$ responding they "agree strongly" or "agree somewhat" that they would place at least some data in an unrestricted repository. By comparison, only $46.6 \%$ of researchers in medicine agreed strongly or agreed somewhat with this statement. Of course, data sharing involves a much higher level of openness and disclosure than tweeting, but Tenopir et al.'s (2011) findings suggest that ecologists are significantly more willing to participate in open scientific dialogues than other types of researchers. Therefore, it is problematic to view the marine ecology and conservation community as being a representative sample of the scientific community on the whole when it comes to discussion of open science.

Though some articles have explored Twitter in other fields of science (for example Neill et al.'s (2013) article on emergency medicine and Stafford and Bell's (2012) article on cognitive science), I suggest further research is needed in this area to better understand how researchers across the disciplines use Twitter. Fortunately, the work of Darling et al. (2013) provides an excellent methodological framework for investigations into other scientific fields, which may or may not diverge from the marine ecology and conservation community in their attitudes toward and use of Twitter.

Twitter can also play a fundamental role in the scientific process that Darling et al. (2013) do not address here-not only does Twitter connect researchers to potential collaborators with data to share, but it also provides its own unique kind of raw data in the form of tweets themselves. For sociologists, anthropologists, and researchers in related fields, Twitter's usefulness is fairly evident, but researchers from beyond the social sciences have also looked to Twitter for data. Recent examples include using Twitter to track patterns of drug abuse (Chary et al. 2013, Hanson et al. 2013) and to investigate the role of circadian rhythms in mood (Golder and Macy 2011). Twitter also has potential applications in public health research as a disease surveillance tool that could provide early warning of outbreaks (Sofean and Smith 2012, Burton et al. 2012). Twitter's importance as a data source is perhaps currently limited by its relatively low adoption among the broader Internet-using public: in a 2012 Pew Research Center study, a mere $16 \%$ of Internet users reported using 
Twitter, and those that do tweet are disproportionately young and urban-based (Duggan and Brenner 2013). Nonetheless, as more scientists open their own Twitter accounts, it is likely that researchers across a variety of disciplines will realize new uses of tweets and Twitter data as the fodder for scientific research. Thus, Twitter is a tool that not only serves the important functions that Darling et al. (2013) address, but can be potentially leveraged across the entire scientific research process.

\section{References}

Burton, S.H., Tanner, K.W., Giraud-Carrier, C., West, J.H., and Barnes, M.D. 2012. "Right time, right place" health communication on Twitter: value and accuracy of location information. Journal of Medical Internet Research 14: e156. CrossRef

Chary, M., Genes, N., McKenzie A., and Manini, A.F. 2013. Leveraging social networks for toxicovigilance. Journal of Medical Toxicology 9: 184-191. CrossRef

Darling, E.S., Shiffman, D., Côté, I.M., and Drew, J.A. 2013. The role of twitter in the life cycle of a scientific publication. Ideas in Ecology and Evolution 6: 32-43. CrossRef

Duggan, M. and Brenner, J. 2013. The Demographics of Social Media Users-2012. Pew Research Center,
Washington, D.C., USA. http://pewinternet.org/ / media/Files/Reports/2013/PIP SocialMediaUsers.pdf

Golder, S.A. and Macy, M.W. 2011. Diurnal and seasonal mood may vary with work, sleep, and daylength across diverse cultures. Science 333:18781881. CrossRef

Hanson, C.L., Burton, S.H., Giraud-Carrier, C., West, J.H., Barnes, M.D., and Hansen, B. 2013. Tweaking and tweeting: exploring twitter for nonmedical use of psychostimulant drug (adderall) among college students. Journal of Medical Internet Research 15: e62. CrossRef

Neill, A., Cronin, J.J., Brannigan, D., O’Sullivan, R., and Cadogan, M. 2013. The impact of social media on a major international emergency medicine conference. Emergency Medicine Journal. CrossRef

Sofean, M. and Smith, M. 2012. A real-time disease surveillance architecture using social networks. Studies in Health Technology and Informatics 180:823-827.

Stafford, T. and Bell, V. 2012. Brain network: social media and the cognitive scientist. Trends in Cognitive Sciences 16: 489-490. CrossRef

Tenopir, C., Allard, S., Douglass, K., Aydinoglu, A.U., Wu, L., Read, E., Manoff, M., and Frame, M. 2011. Data sharing by scientists: practices and perceptions. PLoS ONE 6: e21101. CrossRef 